\title{
Evaluation in sexual and reproductive health
}

Knowledge in reproductive health and sexuality has made great strides as the result of research training initiatives. An important example is the Inter-Institutional Training Program for Research Methodology in Gender, Sexuality, and Reproductive Health, involving the Institute of Collective Health (Federal University in Bahia), Institute of Social Medicine (Rio de Janeiro State University), Center for Population Studies (State University in Campinas), Sergio Arouca National School of Public Health (Oswaldo Cruz Foundation), and Institute of Health (São Paulo State Health Secretariat), which have held regionalized courses and scholarship programs with support from the Ford Foundation and from the Department of Science and Technology, Brazilian Ministry of Health. The program has trained 250 students and 97 scholarship holders, and the results can be consulted in other publications as well as in this current Supplement, with articles by scholarship holders and faculty on "Evaluation in Sexual and Reproductive Health".

This approach was prioritized in order to improve rationality in the sectoral interventions focusing on sexual and reproductive health, which have grown considerably but without a corresponding evaluation of their implementation and results.

Part of this Supplement relates to the HIV/AIDS epidemic. Parker analyzes the changes brought about by the epidemic in sexuality as a field of research and human experience. Santos et al. analyze the contexts of vulnerability to HIV, indicating which prevention strategies foster women's empowerment. Oliveira identifies factors that facilitate (or impede) access to and continuity of AIDS treatment. Ferraz \& Nemes analyze the tensions between the guidelines of the Brazilian National STD/AIDS Program and local technological arrangements in the implementation of prevention activities.

Another set of articles addresses the issue of equity in access to health services. Vieirada-Silva \& Almeida Filho contribute to the theoretical underpinnings for research on this theme, working with these concepts and the relations between equity, justice, and social determination of health-disease. Albuquerque et al. analyze the coverage of Pap smear screening and defend women's role as protagonists in prevention activities. Novaes \& Mattos study the non-utilization of mammography and recommend focused measures for women who are excluded from health services. Barbosa \& Facchini discuss access to and quality of gynecological care for women engaging in homoerotic practices.

Three articles approach important aspects pertaining to reproductive health care. Heilborn et al. study perceptions concerning contraception among female users of the Unified National Health System (SUS). Marinho et al. investigate factors associated with the use of contraceptives during sexual initiation, in three Brazilian State capitals. Nagahama develops and applies an instrument for evaluating the implementation of contraceptive care.

Contributing to the basis for research, Schraiber et al. discuss the interrelationship between theoretical, methodological, and ethical aspects in the study of gender violence. Likewise, Menezes \& Aquino provide a recent overview of collective health studies on abortion, seeking to identify gaps and challenges for research on the theme.

It is hoped that this Supplement will provide elements that contribute to improving health care and policymaking, as well as to provide the basis for reproductive choices with autonomy, so that women and men can experience them without risk to their health.

Regina Maria Barbosa

Núcleo de Estudos de População, Universidade

Estadual de Campinas, Campinas, Brasil.

rbarbosa@nepo.unicamp.br

Estela M. L. Aquino

Instituto de Saúde Coletiva, Universidade Federal da Bahia, Salvador, Brasil.

estela@ufba.br

\author{
Maria Luiza Heilborn \\ Instituto de Medicina Social, Universidade do Estado \\ do Rio de Janeiro, Rio de Janeiro, Brasil. \\ heilborn@ims.uerj.br \\ Elza S. Berquó \\ Centro Brasileiro de Análise e Planejamento, \\ São Paulo, Brasil.
}

